\title{
Linfangite granulomatosa de genitália infantil: relato de caso e revisão da literatura
}

\section{Granulomatous lymphangitis of children's genitalia: report of a case and review of the literature}

Ana Paula Camargo Martins'; Camila Deneka Arantes Souza²; Fabiana Massae lanaguihara; Mário Rodrigues Montemór Netto ${ }^{4}$; Lúcia de Noronha ${ }^{4}$

unitermos
Pênis
Linfangite
Linfedema
Doença de Crohn

\section{resumo}

Linfangite granulomatosa de genitália não-infecciosa é causa rara de linfedema genital autolimitado e idiopático em crianças ${ }^{(4,6,9)}$. A maioria dos casos de linfedema com granuloma não-infeccioso de genitália em pacientes jovens ocorre em associação à doença de Crohn subseqüente ou concomitante $\mathrm{e}^{(1,3,4,9)}$. $\mathrm{O}$ caso relatado é de um menino de 14 anos que apresentava história de linfedema genital principalmente em região dorsal do corpo do pênis, poupando prepúcio, parte distal do pênis e saco escrotal. Estudos laboratoriais não revelavam doenças sistêmicas. O exame anatomopatológico da peça revelou tratar-se de linfangite granulomatosa não-infecciosa.

Non-infectious granulomatous lymphangitis of genitalia is a rare cause of self-limited and idiopathic genital lymphoedema in children ${ }^{(4,6,9)}$. Most cases of lymphoedema with non-infectious genital granulomas in young patients occur subsequent to or concomitant with Crohn's disease $e^{(1,3,4,9)}$. The case described is of a 14-yearold boy with history of genital lymphoedema mainly on the dorsal region of the body of the penis, sparing the prepuce, the distal part of the penis and the scrotum. Laboratory studies did not reveal systemic diseases. The histopathological analysis showed it was non-infectious granulomatous lymphangitis.

key words

Penis

Lymphangitis

Lymphoedema

Crohn's disease

1. Bióloga do Laboratório de Patologia Experimental; aluna de mestrado na Pontifícia Universidade Católica do Paraná (PUCPR).

2. Acadêmica de Medicina da PUCPR.

3. Médica cirurgiã pediátrica.

4. Médico patologista.

5. Patologista pediátrica do Serviço de Anatomia Patológica do Hospital das Clínicas do Paraná (HC-PR); professora do Setor de Ciências Biológicas e da Saúde da PUCPR; doutora em Patologia Pediátrica. 


\section{Introdução}

O linfedema de genitália é mais comum em idosos, secundário às neoplasias malignas pélvicas e abdominais ou sua terapia ${ }^{(3,4,9)}$. O linfedema peniano isolado é raramente descrito em crianças e está normalmente associado ao linfedema escro$\operatorname{ta}^{(1,6,8,9)}$. O linfedema de genitália é raramente relacionado, em crianças, com neoplasias ou doenças infecciosas (filariose, linfogranuloma venéreo ou inguinal) ${ }^{(9)}$. A maioria dos casos de linfedema com granuloma não-infeccioso (linfangite granulomatosa não-infecciosa) de genitália em pacientes jovens está associada ao desenvolvimento de doença de Crohn subseqüente ou concomitante ${ }^{(1,3,4,9)}$. Uma minoria apresenta granulomatose orofacial (queilite granulomatosa e síndrome de Melkersson-Rosenthal) $)^{(1,3,4,5,9)}$. As causas mais comuns de linfedema genital (pênis e escroto) em crianças são: linfedema congênito (doença de Milroy), trauma e linfedema idiopático(1, 3,4,9). A descrição histológica da linfangite granulomatosa nãoinfecciosa revela derme edematosa com bandas de colágeno espaçadas com telangiectasias e linfangiectasias. Dentro dos vasos linfáticos dilatados estão ninhos de células gigantes multinucleadas e macrófagos epitelióides misturados aos linfócitos, sem corpos estranhos ou necrose central ${ }^{(1,3-5,7-9)}$.

\section{Relato de caso}

B., sexo masculino, branco, 14 anos, natural de Ponta Grossa, PR, apresentou-se com história de tumefação genital de início aproximado aos 12,5 anos. Ao exame físico observava-se linfedema em três quartos da circunferência peniana, principalmente em região dorsal do corpo do pênis, poupando prepúcio, parte distal do pênis e saco escrotal (Figura 1). $\mathrm{O}$ aspecto era infiltrativo e endurecido, lembrando casca de laranja, sem sinais flogísticos ou dor. Relatava maior intensidade do linfedema em dias quentes e após atividade física. Negava disúria ou outros sintomas associados. Peso, altura, desenvolvimento psicomotor e sexual eram adequados para a idade cronológica ${ }^{(8)}$. O paciente demonstrava excelente padrão socioeconômico-cultural, sem contatos sexuais ou história de abuso e bons hábitos de higiene. Negava história de trauma, procedimentos cirúrgicos, picadas de inseto, doenças sistêmicas atuais ou pregressas, sintomas gastrointestinais ou respiratórios. Ao exame físico não apresentava febre, linfadenopatia inguinal, fissuras perianais, fístulas, equimoses, escoriações ou outros achados cutâneos ${ }^{(1,3,8)}$. Os estudos laboratoriais não revelaram doenças sistêmicas, como doença de Crohn, tuberculose, doença fúngica ou sarcoidose (resultados da investigação hematológica e bioquímica normais, velocidade de hemossedimentação [VHS] normal, radiografias de tórax normais, sangue oculto nas fezes negativo) ${ }^{(6-8)}$. Não foi realizada colonoscopia ou biópsia intestinal para diagnóstico de doença de Crohn, pois o paciente não apresentava sinais e sintomas ${ }^{(5)}$. A evolução foi lenta e não houve regressão espontânea. Fez uso de antiinflamatórios não-esteroidais (AINEs) orais, anti-histamínicos e corticóides tópicos, sem regressão ou melhora do quadro. Negava familiares com sinais e sintomas similares ou história familiar de doença de Crohn. Foi submetido a biópsia para diagnóstico, a qual não foi conclusiva devido à superficialidade da amostra. Então se optou por tratamento cirúrgico da lesão com retirada de toda a área acometida. O exame anatomopatológico da peça revelou tratar-se de linfangite granulomatosa não-infecciosa com pesquisa para microorganismos negativa (Figuras $\mathbf{2}$ e $\mathbf{3}$ ). Ao se realizarem consulta de retorno e exames laboratoriais seis meses após a ressecção da lesão, o paciente encontrava-se sem alterações no exame físico, sem recidiva e com exames laboratoriais normais, aguardando a consulta de um ano.

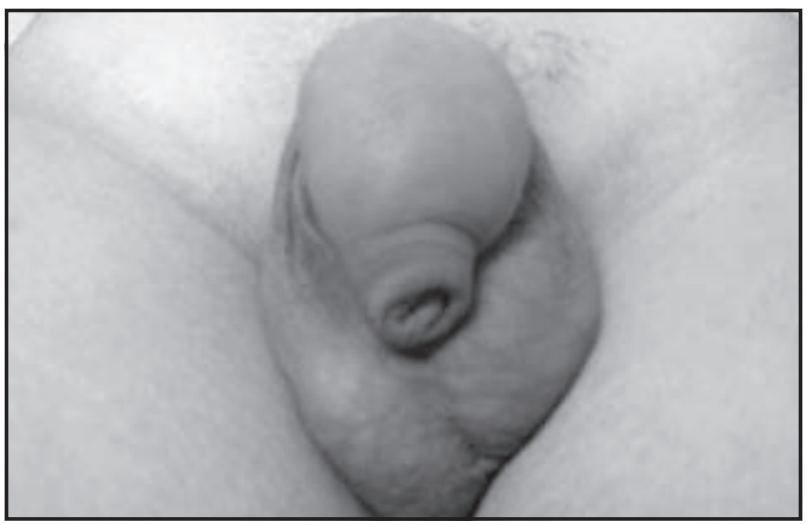

Figura 1 - Tumefação em três quartos da circunferência peniana, afetando principalmente a região dorsal do corpo do pênis, poupando prepúcio, parte distal do pênis e saco escrota

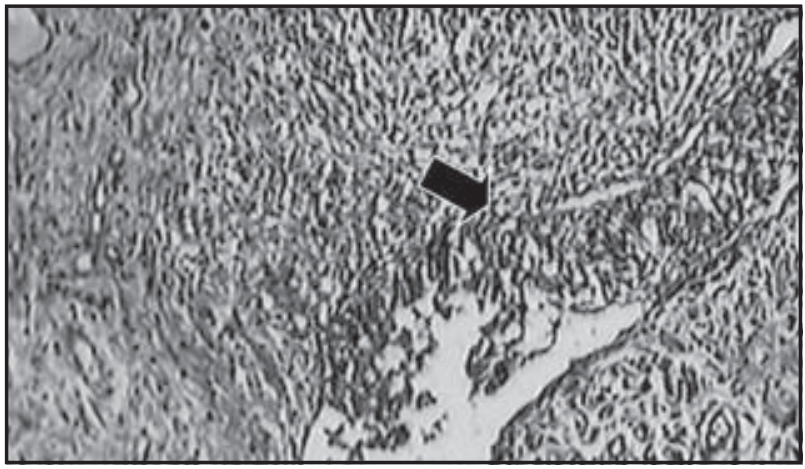

Figura 2 - Lâmina corada com hematoxilina e eosina com aumento de 200 vezes. Podemos observar vaso linfático com granuloma epitelióide comprometendo tanto a periferia como o interior do vaso 


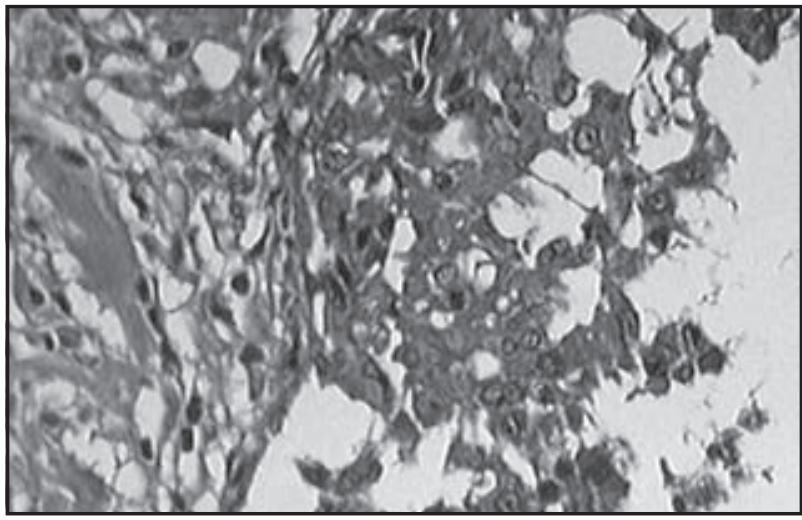

Figura 3 - Lâmina corada com hematoxilina e eosina com aumento de 400 vezes, onde se pode observar um detalhe do granuloma epitelióide mencionado na Figura 2

\section{Discussão}

O linfedema de pênis em crianças pode ser de causa infecciosa, congênita, traumática, neoplásica ou idiopática ${ }^{(3,4,6,7,9)}$. Análise de urina normal, urocultura sem crescimento microbiológico(6), curto tempo de evolução e ausência de febre tendem a eliminar a causa infecciosa ${ }^{(2,6,9)}$. Similarmente, quando não há evidência de alergia, trauma, picada de inseto ou extravasamento de urina ${ }^{(2)}$, estas outras causas são descartadas, como no caso relatado, cujo paciente hígido e jovem apresenta linfedema peniano isolado, sem sinais flogísticos, linfadenopatia, história de trauma, outros achados cutâneos ou alterações laboratoriais(1, 2, 4, 6-8). Linfangite granulomatosa de genitália deve ser considerada no diagnóstico diferencial de linfedema crônico idiopático de genitália, principalmente em crianças e adultos jovens ${ }^{(3,4,9)}$. Devem ser realizados exames físicos, laboratoriais e seguimento para o diagnóstico precoce da doença de $\mathrm{Crohn}^{(3,4,9)}$, a qual pode afetar qualquer segmento do trato gastrointestinal, da boca até o ânus, e provocar lesões extra-intestinais, mesmo que raras, incluindo a linfangite granulomatosa não-infecciosa de genitália ${ }^{(1,3,4,7-9)}$. Para o diagnóstico de doença de Crohn é necessário o achado histológico de granulomas de células gigantes epitelióides não-caseoso da lesão, em associação a achados similares no reto e no canal anal ${ }^{(1,4,5,7-9)}$. O paciente estudado, não apresentou sinais ou sintomas de doença de Crohn. Sugere-se que a linfangite granulomatosa de genitália deva representar uma forma frustra da doença de Crohn, devido às coincidências entre linfangite granulomatosa de genitália, doença de Crohn e granulomatose orofacial ${ }^{(1,3-5,9)}$. Linfangite granulomatosa de genitália externa é uma causa rara de linfedema genital, principalmente em crianças e adultos jovens. Este achado deve alertar os médicos quanto à possibilidade de doença de Crohn presente ou futura ${ }^{(1,3,4,9)}$. Ainda não é claro se a reação granulomatosa genital está sempre associada à doença de Crohn ou é de etiologia ainda não identificada.

\section{Referências}

1. AGGETT, P. J. et al. Atypical genital involvement in a child with Crohn's disease. J Pediatr Gastroenterol Nutr, v. 15, p. 330-3, 1992.

2. ATHERTON, D. J. et al. Genital Crohn's disease in a 6-yearold boy. Br Med J, v. 1, p. 552, 1978.

3. CARLSON, J. A. Case 2: by99-6307 presented in the USCAP 2002.

4. CARLSON, J. A. et al. Granulomatous Iymphangitis of the scrotum and penis: report of a case and review of the literature of genital swelling with sarcoidal granulomatous inflammation. J Cutan Pathol, v. 28, n. 8, p. 419-24, 2001

5. CostA, A. L. et al. Melkersson-Rosenthal syndrome: clinicopathologic study of one case. Arq Bras Oftalmol, v. 64 , p. 573-5, 2001

6. LAU, J. T. K.; ONG, G. B. Acute idiopathic penile edema: a separate clinical entity? J Urol, v. 126, p. 704-5, 1981

7. McCALLUM, D. I.; GRAY, W. M. Metastatic Crohn's disease. Brit J Dermatol, v. 95, p. 551-4, 1976

8. MCCALLUM, D. I.; KINMONT, P. D. Dermatological manifestations of Crohn's disease. Brit J Dermatol, v. 80, p. 1-8, 1968.

9. MOR, Y. et al. Granulomatous lymphangitis of the penile skin as a cause of penile swelling in children. J Urol, v. 158, n. 2, p. 591-2, 1997.

\begin{tabular}{l|l} 
Endereço para correspondência \\
\hline Lucia de Noronha \\
Pontifícia Universidade Católica do Paraná \\
Setor de Ciências Biológicas e da Saúde \\
Laboratório de Patologia Experimental \\
Rua Imaculada Conceição, 1.155 - Prado Velho \\
CEP 80215-901 - Curitiba-PR
\end{tabular}

